\title{
CRYPTO-CANCER OF LUNG
}

\author{
By Maurice Davidson, M.A., D.M. (Oxon.), F.R.C.P. (Lond.) \\ Cuns ilting Physician to the Brompron Hospital; Sometime Associate Physician to the Royal Cancer (Marsden) Hospital \\ and A. D. Thomson, M.A., M.D. (Cantab.), M.R.C.P. (Lond.) \\ Pathologist, Blant-Sutton Institute, Middlesex Hospital
}

Nearly a quarter of a century ago Rendle Short $^{3}$ called attention to a condition which he then described as 'crypto-empyema.' In the cases which he reported, repeated exploration of the chest with needle and syringe, even under an anaesthetic, failed to discover the whereabouts of suspected pus, the diagnosis of empyema being established only by a subsequent exploratory thoracotomy.

The diagnosis of lung cancer, though usually evident at a fairly early stage of investigation, may occasionally present real difficulty, and from time to time examples still occur in which the ' cryptic' character of the primary bronchial growth is the outstanding feature of the clinical picture. In the following case, which must be included in this category, many of the phenomena were so difficult and unusual that we feel they are deserving of a place in, the literature of the subject.

The patient was an unmarried woman of 57 , who had been employed for 30 years on secretarial work. In the early part of her life she had suffered from occasional migraines; apart from these, she had enjoyed good health, and was an energetic worker. In March 1953 she complained of considerable shortness of breath, associated with bronchitis (she had been for some years a heavy cigarette smoker). Her condition at this time was sufficiently serious to demand full investigation, and she was taken into the London Clinic under the care of one of us (M.D.) for the purpose. On clinical examination of the chest there were signs of dry bronchitis, with occasional bronchial spasm; no tubercle bacilli were found in the sputum; except for the first 24 or 36 hours there was no pyrexia. X-ray examination of the chest at that time showed no shadows of pathological significance. She was kept at complete rest in bed and was given daily injections of penicillin for a week. At the end of this period the bronchitis had completely cleared up, she had no further respiratory distress, and she was able to leave the nursing home and return to her ordinary work. She was strongly advised to give up smoking altogether; this she did, and in due course she ceased to have any desire for a $\vec{\sigma}$ cigarette. There was no recurrence of the bron- $\frac{\rho}{0}$ chitis. As a substitute for cigarette smoking she $\frac{\mathscr{O}}{3}$ took to eating more sweets, and as a result she $\frac{3}{\dot{\omega}}$. put on a considerable amount of weight; her $\omega$ general health remained satisfactory.

In the early autumn of I954 she complained of $\omega$ some aching pain in the lower part of the left leg. 今 This, though not very severe, was sufficient to be $\circ$ a source of annoyance and was persistent. In October of that year she was seen by Mr. K. $\mathcal{D}$ Nissen at the Royal National Orthopaedic Hos- $\frac{\mathbb{D}}{0}$ pital. X-ray examination of the leg showed a $\underset{\mathbb{D}}{\mathbb{D}}$ 'fatigue-fracture' of the left lower fibula. This ran a normal course, without any special treatmeng and by January 1955 she was practically free from $\overrightarrow{0}$ pain and able to get about as usual withou on trouble. On April 4 she saw Mr. Nissen agai for a routine follow-up; she then complained of a little pain over the left trochanter, and was a little anxious in case there might be some disease in the hip. Nothing abnormal was found on $\frac{0}{D}$

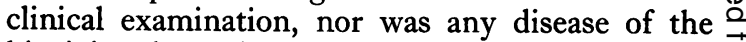
hip-joint shown by a skiagram.

About a month later the pain in the left leg was definitely worse, and was radiating from the region of the left hip down the outer side of the thigh. She was then taken to see Sir Francis Walshe, who found no clinical evidence of any lesion of the nervous system, but urged further and more extensive $\mathrm{X}$-ray examination. This was accordingly carried out at the Royal National Orthopaedic Hospital. The skiagrams showed a deposit in the left ilium adjacent to the lower part of the sacro-iliac joint (Fig. I). Dr. Campbell Golding and Mr. Nissen took a very grave view of the condition, feeling that it was almost certainly malignant in character. Clinically there was nothing abnormal to be found either in the hip or in the back, or in any of the usual primary sites such as thyroid or breasts. X-ray examination of the chest, moreover, showed no definite abnormality. The possibility of multiple myelomatosis was considered, but X-ray examination of other bones in the body showed no osseous lesions else- 


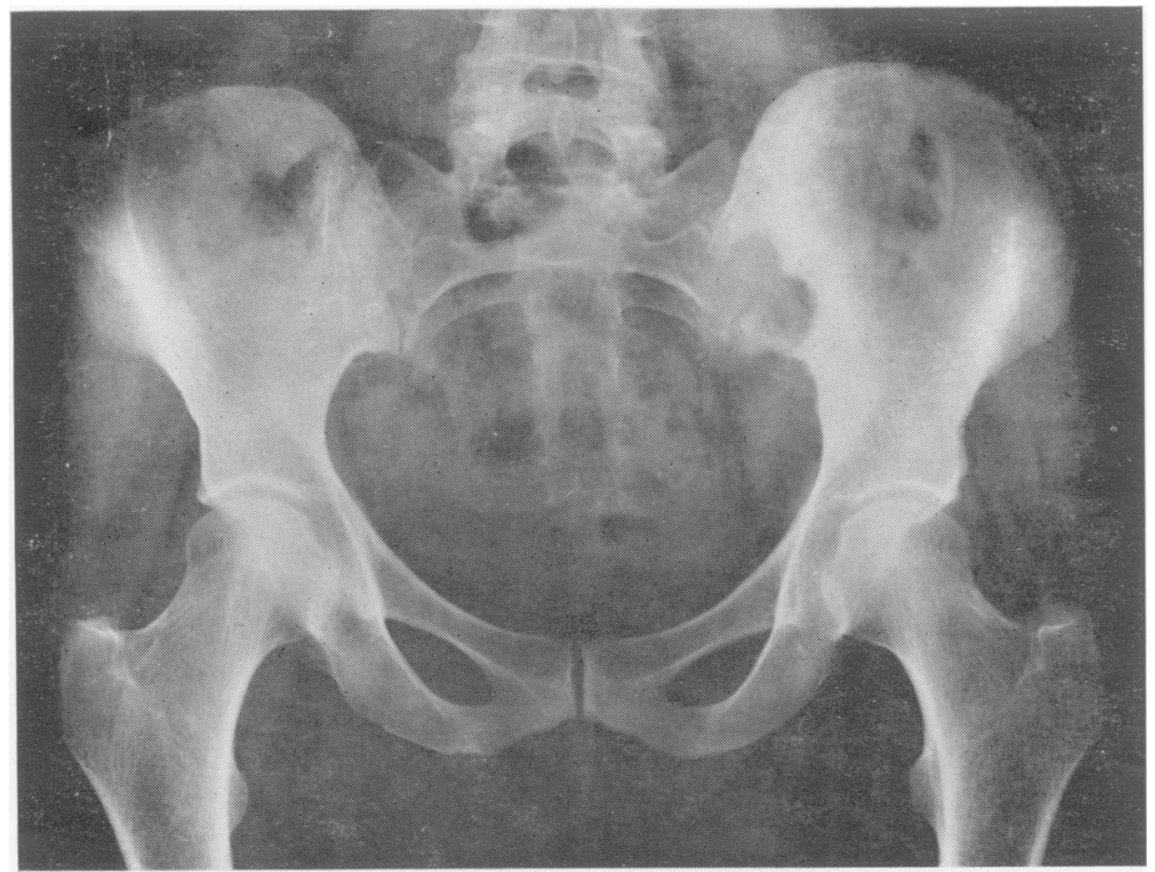

FIG. 1.-X-ray appearances of pelvis, June I7, 1955.

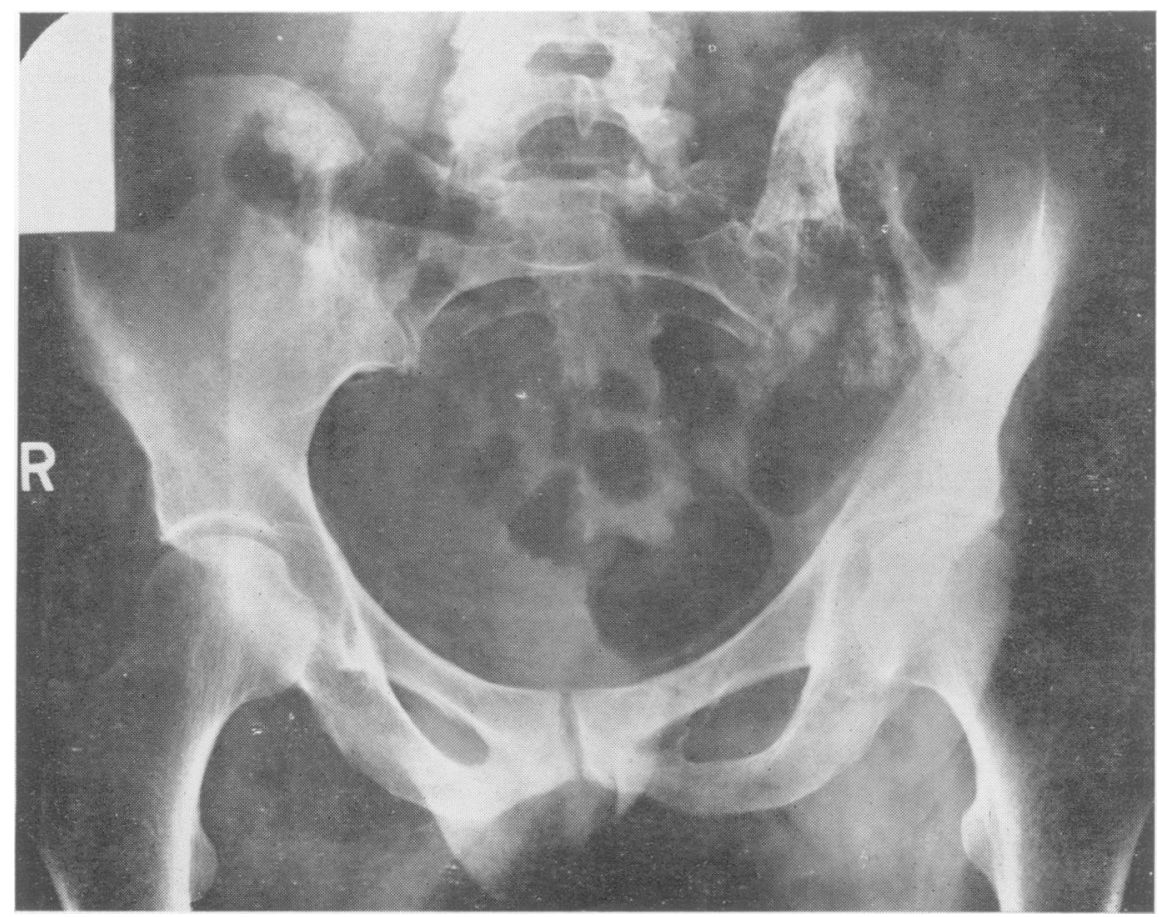

FIG. 2.-X-ray appearances of pelvis, November 7, 1956. 
where; the bio-chemical findings were negative; examination of the urine for Bence-Jones proteose was negative. The result of blood examination was as follows:

B.S.R. $=15 \mathrm{~mm}$

Total white cells: 8 , 100 per c.mm.

Differential count: Neutrophiles Lymphocytes Eosinophiles Monocytes Basophiles

Haemoglobin: $92 \%$ (13.6 g.)

$$
\begin{array}{r}
59.0 \% \\
34.0 \% \\
1.5 \% \\
4.5 \% \\
1.0 \%
\end{array}
$$

P.C.V. $48 \%$

Serum calcium: $9.9 \mathrm{mg} . \%$

Alkaline phosphatase: 8.6 units

Inorganic phosphate: $3.6 \mathrm{mg} . \%$

Total plasma protein: $5.6 \mathrm{~g} . \%$

Plasma albumin: $3.0 \mathrm{~g} . \%$

Plasma globulin: $2.6 \mathrm{~g} . \%$

Albumin/globulin ratio $=\mathrm{I} .2$

The patient was now transferred to the care of Professor Windeyer at the Middlesex Hospital. He felt that in the circumstances no useful purpose would be served by an elaborate search for a primary lesion, but that the best thing that could be done in the patient's interest was to give her radiation directly over the diseased area of bone in the hope of affording real relief from the pain, which had by this time become severe.

Deep X-ray therapy was accordingly begun on July 6 and was continued for 17 days, I 3 treat$\mathrm{m}=n$ ts being given during this period. The relief o stained was considerable, and she was enabled to get on with her work in comfort for about three $m$ onths, pain having practically disappeared. In October the pain recurred in the left buttock, hip and thigh; and a second course of radiation was given, similar to the first. Again she obtained dsfinite relief, though occasionally she had to take codeine to keep the pain completely under control.

In January 1956 she attended again as an outpatient for routine examination. No marked increase of bone destruction was evident in skiagrams, which, however, showed sclerosis round the deposit in the left ilium, presumably resulting from the radiation. Skiagrams of the chest still showed nothing definitely indicative of a lung lesion (Fig. 3). From this time onwards she remained tairly well (the occasional pain in her left leg being adequately controlled by one tablet of Codein (io.), until June of this year when she went for a short holiday in the south of England.

While away she suddenly had a major epileptiform seizure with tirst tonic and then clonic convulsions; she was completely unconscious for nearly an hour, and on recovery had no knowledge of what had happened. On the following morning she appeared perfectly well: This incident natur- ally suggested the presence of metastatic lesions in the brain, and on her return to London she saw $\frac{3}{8}$ Dr. Kremer at the Middlesex Hospital. He found $\stackrel{\varrho}{C}$ no localizing signs in the central nervous system, but in view of the severity of the attack and of her $\stackrel{=}{?}$ natural apprehension of its possible recurrence, $\overline{0}$ he agreed that some form of sedative should be음 given and prescribed capsules of phenobarbitone $\frac{\bar{c}}{\bar{T}}$ and epanutin, to be taken twice daily. She $\stackrel{\mathbb{Q}}{\propto}$ remained fairly comfortable on the whole until about the middle of August, when she began to ${ }^{\infty}$ get pain over the area corresponding to the distri-. bution of the left anterior crural nerve, and at the $\overrightarrow{\vec{\omega}}$ same time she complained of some dysphagia.

$\mathrm{X}$-ray examination of the pelvis showed that the area of bone destruction in the left ilium had 3 . increased; no abnormality was seen on indirect $\dot{\omega}_{j}$ laryngoscopy, and a barium swallow revealed no $\dot{\omega}$ structural disease of the oesophagus. About this time she also began to experience noises in the if ears and some deafness. She was still able to $N$ come up as an out-patient, and a further course 옹 of deep X-ray therapy was given (I4 treatments over a period of 20 days). By September 21 she $D$ was almost entirely free from pain in the leg, and $\stackrel{\square}{\square}$ needed only an occasional dose of codeine. Her $\frac{\mathbb{D}}{3}$ general condition, however, had undergone marked $\underset{\mathbb{\Phi}}{\mathbb{D}}$ deterioration; she had lost a lot of weight (I I 110 in five weeks), and the dysphagia was much of worse. Fluids could be swallowed without grest. difficulty, but solid food seemed to stick in the pharynx and ultimately to cause vomiting-this was usually preceded by a bout of coughing. On October 2 she was admitted to Queen Mary ward under Professor Windeyer for further investi- $\stackrel{\mathbb{Q}}{\varrho}$ gation.

Examination of the pharynx and larynx now showed weakness of the right side of the pharynx, with sensory loss in this area, and weakness of the right palate; there was almost complete paralysis of the right vocal cord. Examination of the right 3 . ear showed only some slight crusting in the external auditory meatus, but there was marked perceptive deafness. It was presumed that these $\delta$ recent phenomena were in all probability due to metastatic deposits at the base of the skull, and a 은 course of deep X-ray therapy was given in this $>$ region in the hope of affording some relief to the symptoms. Complete examination of the naso- $\bar{N}$ pharynx, breasts, thyroid, and renal tract for a primary lesion gave negative results. Further $\tilde{O}$ $\mathrm{X}$-ray examination of the bone lesions showed $\underset{\mathrm{N}}{\mathrm{N}}$ some destruction of the fifth lumbar vertebra and 0 some metastatic deposits in the upper third of the 6 left femur. In the hope that the metastases $\mathbb{\mathbb { D }}$ might be hormone-sensitive, she was started on a ? course of intramuscular injections of $50 \mathrm{mg}$. of $\bar{T}$ testosterone phenyl proprionate twice weekly, and 


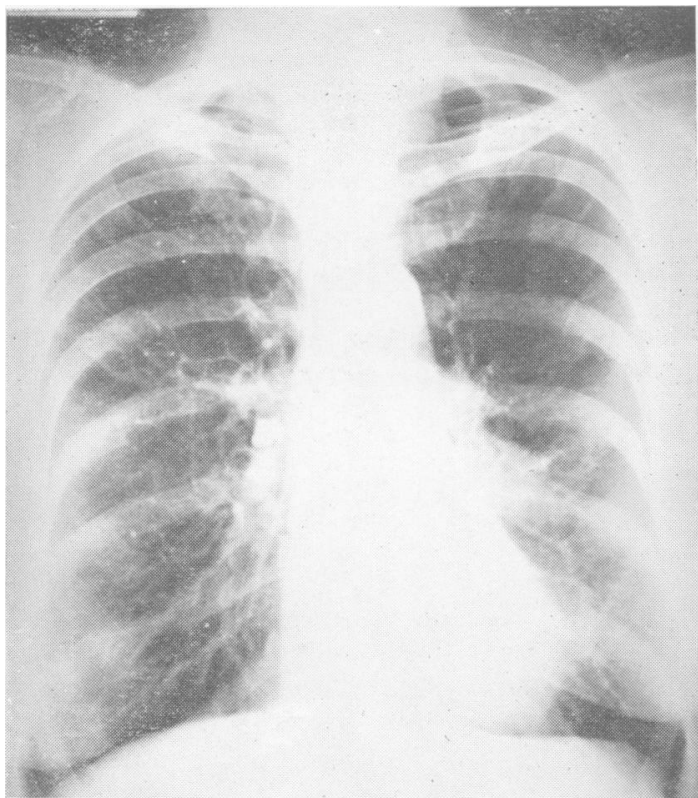

FIG. 3.-X-ray appearances in chest, June I7, 1955.

left hospital on December I, arrangements having been made for her to have the injections continued until further notice.

For two months she remained at home, being by this time quite unable even to get about, much less to do any work, and having been retired by her employers on a suitable pension. The pain in her pelvis and leg was now so bad that it was necessary to give her tablets of Codein Co. every two hours. The difficulty in swallowing persisted; she lost all desire for food of any kind, could take only fluids, and was becoming emaciated. On February 2, 1957, she had three severe major epileptiform fits in succession (at intervals of ro or I 5 minutes), and was therefore removed as soon as possible to the Middlesex Hospital, arriving there in the ambulance unconscious. On being seen by one of the residents soon after admission to the ward she was more or less comatose, and resisted all attempts to examine her. By February 4, though somewhat confused mentally, she was more co-operative and could be examined without resistance. The edge of the liver could be felt about finger-breadths below the right costal margin; the breath had an odour suggestive of uraemia; the blood urea was found to be $45 \mathrm{mg} . \%$. During the preceding 36 hours her fluid intake had not exceeded one pint. There was obvious pain with all movements of the left shoulder and the left hip; there was also tenderness around the head of the humerus, over the ribs, and over the medial wall of the axilla. The right

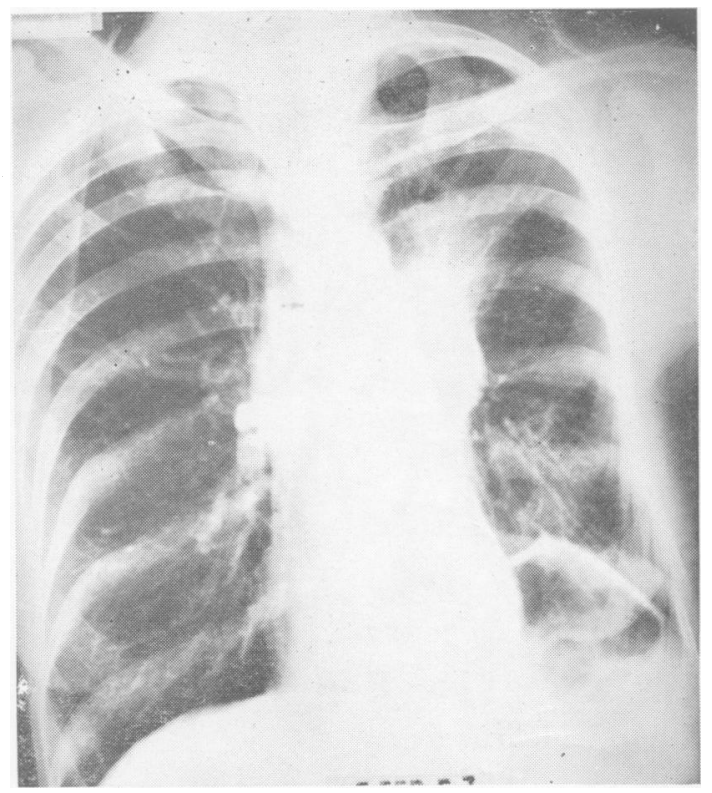

FIG. 4.-X-ray appearances in chest, February 5, 1957.

fundus oculi showed some blurring of the medial edge of the disc, suggestive of early papilloedema.

$\mathrm{X}$-ray examination of the bones showed extension of the deposits in the left ilium and left pubic ramus (Fig. 2). There were, moreover, deposits in the left femoral cortex, in the fourth rib, and in the scapula; and a fracture through the outer border of the scapula. The skiagram of the chest now showed an obvious opacity in the left hilum, such as would ordinarily suggest a partial collapse of the left upper lobe resulting from partial obstruction of the bronchus supplying this area (Fig. 4). The left side of the diaphragm was high, and the radiologist reported that previous screening had shown definite diaphragmatic hemiparalysis. As a last forlorn measure of relief she was given a final course of deep X-ray therapy ( 12 treatments over a period of 16 days) and further injections of one of the hormone preparations. Pain was severe and had to be controlled by frequent doses of codeine by day and dispirin and nepenthe by night; she also received soneryl, phenobarbitone, and linctus heroin. On March I she had another attack of ' grand mal,' less severe than the former fits, but accompanied by vomiting and followed by a period of unconsciousness lasting about 20 minutes. The next morning she had no recollection of the events of the previous evening. On March 15 , owing to the great demand for admissions, she was discharged to a private nursing home.

From this time onwards she went downhill very 


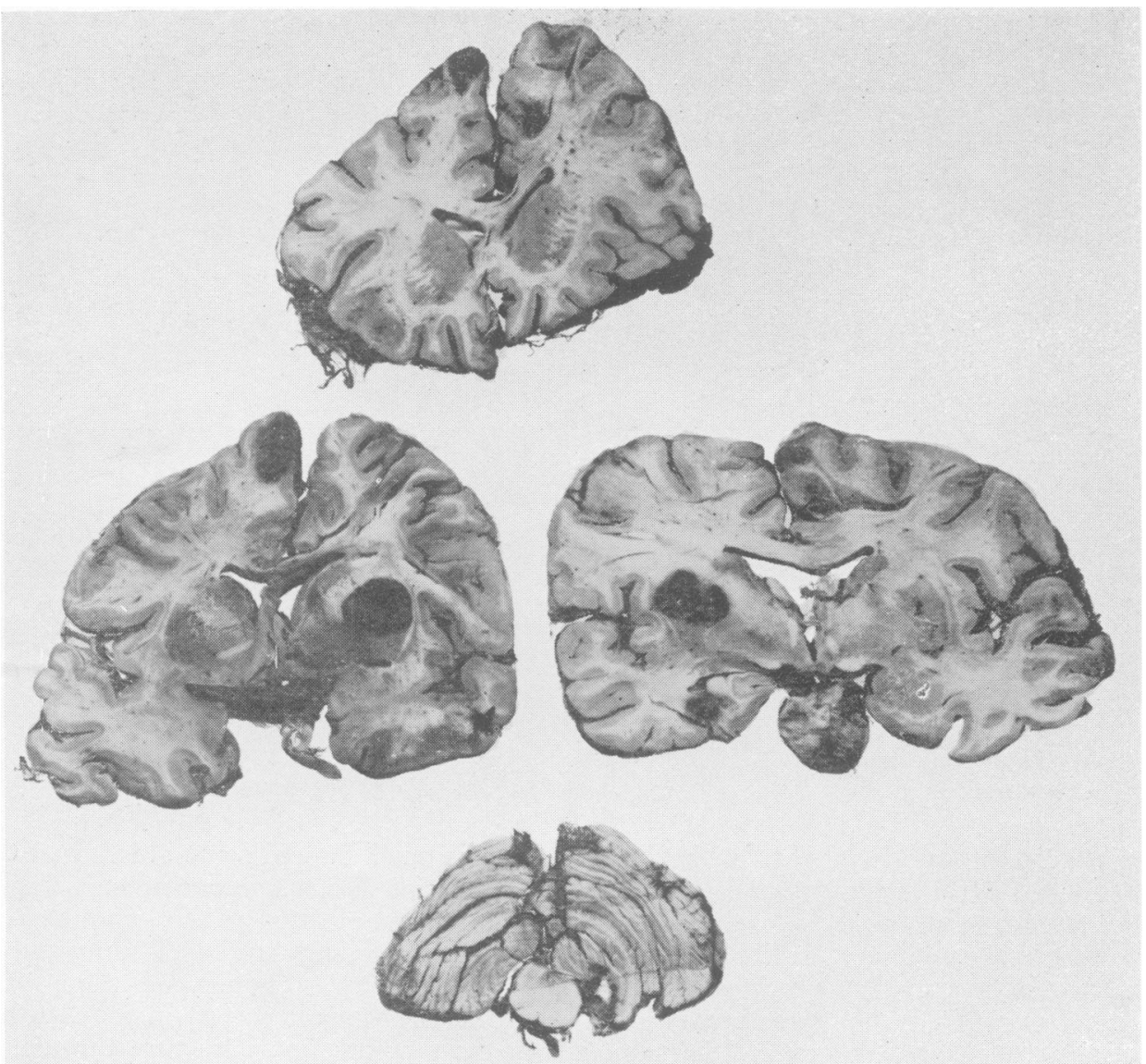

Fig. 5.-Macroscopic appearances of brain showing multiple secondary deposits.

rapidly, becoming more emaciated and hardly taking any food, except very small quantities of milk or broth. Several more fits similar to the previous attacks took place. Pain became so severe on the slightest movement that very large doses of largactol, morphia, and heroin had to be given every four hours. Despite the distressing bodily condition, she would rouse herself at intervals to talk to her nurses or to the few intimate friends whom she was anxious to see; and though at times a little confused, her mind remained clear until a few hours before death, which occurred early on the morning of May 8, 1957.

\section{Autopsy Findings}

At the post-mortem examination the patient showed marked cachexia and weighed only $70 \mathrm{lb}$. Internally there was brown atrophy of the heart, but it was otherwise normal. The lungs were the site of the primary pathology and showed a I-in. diameter carcinoma arising from the left upper lobe bronchus with occlusion of the lumen and invasion of the surrounding lung tissue. The left hilar lymph nodes were replaced by tumour and measured up to $I$ in. in diameter. The lung parenchyma was emphysematous apart from partial collapse of the left upper lobe, and there were inactive calcified tuberculous nodes in the right hilum. The pleural surface was not involved by tumour and there was no pleural effusion. No tumour could be detected elsewhere in the chest and the cervical and axillary nodes were free from invasion. There was no abnormality in the neck and the thyroid gland appeared normal.

In the abdomen the peritoneum appeared entirely normal with no ascites. The liver and spleen were of normal size and consistency and contained no tumour. There were solitary tumour nodules in both adrenal glands measuring $\frac{3}{4}$ in. diameter, and both kidneys contained multiple metastatic tumour tissue up to $\frac{1}{2}$ in. 
diameter in both cortices. No other tumour involvement was apparent elsewhere in the abdomen, and the pelvic viscera, including the uterus and ovaries, were normal.

The skull was eroded to a diameter of $\mathrm{I}$ in. over the left frontal region and the underlying membranes were tense but tumour-free. The brain tissue contained multiple secondary deposits in all areas involving the grey and white matter of both cerebral hemispheres with a solitary deposit in the cerebellum. These metastases varied from $\frac{1}{2}$ to $2 \mathrm{in}$. in diameter, and the larger ones showed haemorrhage and necrosis in the tumour tissue. In all there were about 30 such deposits and some are illustrated in Fig. 5.

There were multiple tumour deposits in the osseous system, including involvement of thoracic vertebrae $I_{0}$ and $I I$ and lumbar vertebrae 4 and 5 . The left sacro-iliac joint was virtually replaced by tumour and the left ilium was destroyed by growth which extended by direct continuity through the acetabulum to invade the hip joint.

Histologically the primary bronchial tumour showed a well-differentiated columnar cell adenocarcinoma with papillary areas arising from the left upper lobe bronchus, and all the metastases revealed an identical appearance (Fig. 6).

This case illustrates therefore a small, welldifferentiated and slowly growing carcinoma of the bronchus with extensive and widespread metastases which gave rise to the clinical manifestations of the disease, the primary tumour remaining latent until an advanced stage of the illness.

\section{Comment}

The manifestation of the presence of a primary bronchial carcinoma by symptoms due to involvement of other parts of the body by metastatic deposits is, of course, no new phenomenon. As long ago as 1930 Ferguson and Rees ${ }^{2}$ drew attention to a series of nine cases of unsuspected primary lung cancer with secondary deposits in the brain or spinal cord: in many of these there had been no obvious indication of any intrathoracic lesion, the first manifestation of illness being the nervous symptoms. This is now so well recognized that $\mathrm{X}$-ray examination of the chest in cases of hemiplegia, etc., has become almost a routine procedure in most neurological centres.

With regard to the relative frequency with which distant regions are involved there seems to be general agreement. ${ }^{1}$ Apart from the regional lymph nodes, the order of frequency would appear to be the liver, the lungs themselves, the bones, the brain, the kidneys and suprarenals, the pancreas, the heart and pericardium, the thyroid, the

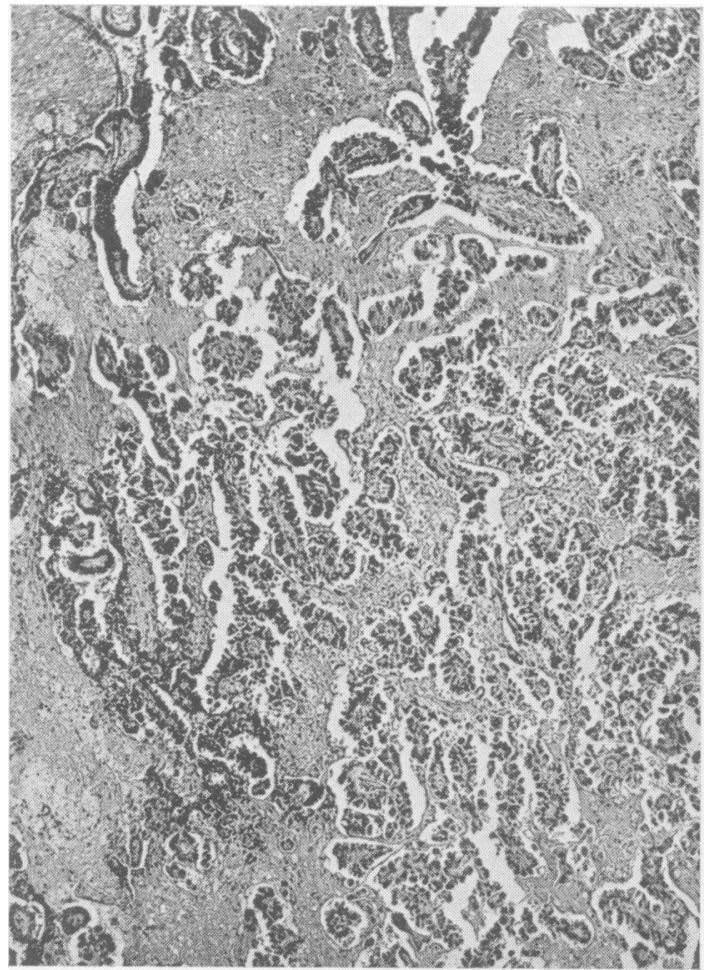

FIG. 6.-Microphotograph of growth $\times 85$, showing papillary adeno-carcinoma.

colon, the stomach and spleen, the gall-bladder, the ovaries. It has been recorded that involvement of bones is occasionally the first cause of symptoms during life, and that this may be a source of distressing errors in diagnosis. One such example has been seen by one of us (M.D.) in a lad of 19 with secondary carcinoma of the lumbar vertebrae due to a primary growth in the bronchus. This, however, is in our experience unusual.

What has impressed us as certainly out of the ordinary in this case is the widespread dissemination of growth in bones and nervous system, manifested over so long a period without the slightest clinical indication of an intrathoracic lesion. It is easy to be wise after the event, and critical examination of the first radiograph of the chest (Fig. 3) suggests that had this patient attended a chest hospital in the first instance, and with symptoms referable to the respiratory system, the presence of the slight opacity in the left lower zone, just below the hilum, might well have led to a bronchoscopic examination; though whether the bronchoscope would at that stage have revealed anything definite in the left upper lobe bronchus is a matter for conjecture, if not for doubt. Of the significance of the last chest X-ray (Fig. 4) 
there can be no question; but this was taken only three months before death, in a patient whose illness had extended over two years, and who had at no time presented as a ' chest case.'

The early diagnosis of primary bronchial carcinoma is still a problem to the thoracic surgeon and it is in the belief that 'crypto-cancer' of the lung is commoner than is generally recognized, even now, that we have ventured to add this case to the literature of the subject.

\section{Acknowledgment}

We are indebted to Professor B. W. Windeyer for his kind permission to make use of his notes on this case and to reproduce some of his radiographs; and also to Mr. Karl Nissen for a similar courtesy.

REFERENCES

I. DAVIDSON, M., SMITHERS, D. W., and TUBBS, O. S. 'The Diagnosis and Treatment of Intrathoracic New Growths, (195I), Oxford University Press, p. 83.

2. FERGUSON, F. R., and REES, W. F. (I930), Lancet i, 738. 3. SHORT, A. R. (1933), Brit. med. F., i, 870.

\section{CARCINOMA OF THE BRONCHUS}

\section{(Postgraduate Medical Journal)}

Price 3s. 9d. post free

\section{INTRODUCTORY}

Maurice Davidson, D.M., F.R.C.P.

THE INCIDENCE AND AETIOLOGY OF PRIMARY CARCINOMA OF THE LUNG

C. E. Drew, M.V.O., F.R.C.S.

\section{MEDICAL ASPECTS}

J. Anderson, M.D., F.R.C.P.

RADIOLOGICAL ASPECTS

G. Simon, M.D., D.M.R.E., F.F.R.

\section{UNUSUAL MANIFESTATIONS}

J. Smart, M.D., F.R.C.P.

CYTOLOGICAL EXAMINATION OF TIIE SPUTUM AND PLEURAL EFFUSION

J. L. Pinniger, D.M., M.R.C.P.

THE SCOPE OF RADIOTHERAPY

Gwen Hilton, D.M.R.E., F.F.R.

SURGERY OF CARCINOMA OF THE BRONCHUS

L. L. Bromley, M.Chir., F.R.C.S.

Published by

THE FELLOWSHIP OF POSTGRADUATE MEDICINE

60, Portland Place, London, W.1

\section{HOW TO GET THERE}

An Address Book for the Medical profession, showing how to reach the various Colleges, Societies, Institutes and Hospitals in or near London

New (Fourth) Edition: 1954

Published by the

Price 2s. 6d. (2s. 10d., post free)

FELLOWSHIP OF POSTGRADUATE MEDICINE 60 Portland Place, London, W.I 